\title{
Rangeland Invasive Plant Management
}

\section{By Joseph M. DiTomaso, Robert A. Masters, and Vanelle F. Peterson}

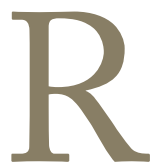

angeland and pastures comprise nearly half of the total land area of the United States. ${ }^{1,2}$ These lands provide a valuable resource for wildlife and recreational activities, as well as livestock grazing. The establishment and spread of invasive plants on rangeland are often symptomatic of long-term cultural practices. ${ }^{3}$ Invasion of many rangeland sites by non-native plants has been facilitated by multiple factors including overgrazing by domestic livestock, purposeful introduction of non-native plants for agricultural purposes, unintentional introduction of non-native plant seeds as a contaminate in crop seed, changes in fire frequency and intensity, and climatic changes that converge to cause shifts in plant community composition.

There are over 300 rangeland weeds in the United States, but perhaps 30 have significant negative impact in the western United States. ${ }^{2}$ Of these, some of the most problematic include downy brome or cheatgrass (Bromus tectorum), medusahead (Taeniatherum caput-medusae), leafy spurge (Euphorbia esula), perennial pepperweed (Lepidium latifolium), Dalmatian toadflax (Linaria dalmatica), and several members of the Asteraceae, including yellow starthistle (Centaurea solstitialis), diffuse knapweed (C. diffusa), spotted knapweed (C. stoebe subsp. micranthos), musk thistle (Carduus nutans), Canada thistle (Cirsium arvense), hawkweeds (Hieracium spp.), and Russian knapweed (Acroptilon repens).

These and other invasive plants can have adverse effects on rangeland and pastures by disrupting vegetation dynamics and reducing ecosystem capacity to recover after disturbance. ${ }^{3}$ The financial impacts of invasive plants in rangelands are substantial and have been estimated to cost ranchers US $\$ 5$ billion annually just for control. ${ }^{4}$ Other impacts to the livestock industry not included in the estimate are the negative effects of invasive plants on yield and quality of forage, livestock poisoning, interference with grazing, supplemental costs associated with managing and producing livestock, and land values. In addition to the livestock industry, invasive rangeland species can decrease wildlife habitat and forage, deplete soil and water resources, and reduce plant and animal diversity.
Mechanical, cultural, biological, and chemical methods have been developed to manage rangeland invasive plants. These methods include mowing, prescribed burning, appropriate grazing management, herbicides, biocontrol agents, and revegetation with desirable plants. ${ }^{1}$ The merits of each control measure and potential for complementary or synergistic interactions when applied in appropriate sequences and combinations should be considered when developing integrated weed management programs. For example, summer burning resulted in a dramatic increase in yellow starthistle germination the following fall and winter. ${ }^{5}$ Thus, using an herbicide treatment in the year following a prescribed burn gave far better control of yellow starthistle compared with an herbicide treatment followed by prescribed burning.

Successful integrated strategies require careful planning that incorporates a long-term approach consisting of prevention programs, education activities, and management approaches. These are designed to diminish negative impacts of invasive plants by improving the invaded plant community to increase its ecosystem function, niche occupation, and competitiveness. These qualities can increase the communities' resistance to reinvasion by other invasive plants. ${ }^{3}$

\section{Invasive Plant Management Strategy}

Land-use objectives vary, depending on the specific site and needs of the rangeland resource manager. Rangeland management objectives include forage production, wildlife habitat improvement, restoration of native vegetation complexes, and recreational land maintenance. While an important objective of any invasive plant management program is to control the undesirable species in the degraded rangeland community, the goal should be restoration of a desired plant community that is less susceptible to invasion and that meets land-use objectives. ${ }^{1,6}$ Developing a desired plant community involves managing community succession using knowledge of site availability necessary for desirable vegetation (created through designed disturbance), differential species availability, and species performance. ${ }^{6}$

To effectively manage invasive plants and to develop a desired plant community, it is necessary to understand the 
biology and ecology of invasive plants and the plant communities they invade. An understanding of such factors as plant demography, propagule dynamics, seedling recruitment, plant growth and development, and methods of reproduction could help identify vulnerabilities of the invasive plant that could be exploited in a management program. In addition, familiarity with other desirable species present, the potential for invasion of uninfested sites within the area, impact of the management strategy on sensitive species and habitats, and soil conditions and range types present are also important. ${ }^{1}$

\section{Components of an Invasive Plant Management Strategy}

The key components of an invasive-plant management strategy include prevention, early detection and eradication of new infestations, monitoring and assessment, containment of large infestations, coordination of efforts among stakeholders, a long-term commitment, and adoption of adaptive management practices. ${ }^{1,3}$

\section{Prevention \\ Emphasis should be placed on the prevention of movement of invasive plant seeds or vegetative propagules from infested areas, the reduction of susceptibility of plant com- munities to invasive plant establishment, and the develop- ment of materials and activities to educate the public about prevention strategies. ${ }^{1,3}$ As part of an effective education program, public awareness of the impacts associated with invasive plants can provide the political support and resourc- es necessary for sustainable invasive-plant management programs.}

\section{Early Detection and Eradication}

An effective eradication program is closely tied to prevention. The key elements of a successful eradication plan are early recognition and rapid, intensive, and aggressive implementation of effective control measures to prevent reproduction and the development of a seedbank. ${ }^{7}$ In most cases, control options in an eradication program are limited to mechanical removal and herbicide treatment, with the objective of eliminating all propagules of the invading species from the site.

\section{Monitoring and Assessment}

One of the most important aspects of developing an invasive weed management strategy is to accurately identify and delineate lands infested with the invasive plants. Knowing where infestations occur and the magnitude of the problem can influence control methods used, can assist in prioritizing where management resources should be deployed, and can enable categorization of areas where eradication, containment, or other management approaches can be achieved. ${ }^{1}$ Monitoring must be continued after control-program initiation so that new invasions can be quickly detected and in order to determine the adequacy of the management plan.
Repeated monitoring provides the information necessary to develop an adaptive management approach that optimizes program effectiveness.

\section{Containment of Large Infestations}

Once an invasive plant is well established and widespread, it is unlikely that eradication can be accomplished without high financial and labor inputs. The objectives under these circumstances are to contain the infestation and to prevent it from spreading. In many cases, intensive restoration efforts may be the only feasible management option. The goals are generally to reduce the impact of the invasive species to an acceptable level and to keep the species from dominating the plant community and substantively altering ecosystem function.

\section{Coordination Among Stakeholders}

A coordinated effort among stakeholder groups and other interested parties, including the general public, private and public landowners, federal, state and county agencies, and environmental organizations will increase management-plan effectiveness. Such programs can reduce duplication of effort, reduce avenues for plant reintroduction, consolidate equipment and labor costs, and decrease the risk of repeating previous failures. ${ }^{1}$ In addition, coordinated management teams are often better positioned to successfully compete for cost-sharing invasive-plant management grants.

\section{Long-Term Commitment}

A long-term commitment of at least three years is necessary in nearly all cases in order to deplete the weed seedbank or resprouting of perennial weeds or to establish the desired community. Once the desired objectives have been attained, a follow-up program is necessary to prevent reinfestation. Grazing management and other practices that contributed to plant invasion need to be changed in order to further rangeland improvement and to make the site less susceptible to rapid reinfestation. ${ }^{1}$ These changes can include manipulating stocking rates, timing, grazing intensity, and other factors.

\section{Adaptive Management Practices}

Adaptive management is closely tied to a monitoring and assessment program and requires establishing land-use goals, developing and implementing management programs based on these goals, monitoring and assessing impacts of management efforts, and modifying goals and management based on new information or observed results. It is often helpful to compare managed areas to untreated sites. This can provide a more effective assessement of the success of the program.

\section{Integrated Pest Management (IPM)}

In wilderness and rangeland systems, the use of a single control method for invasive plant management is often 


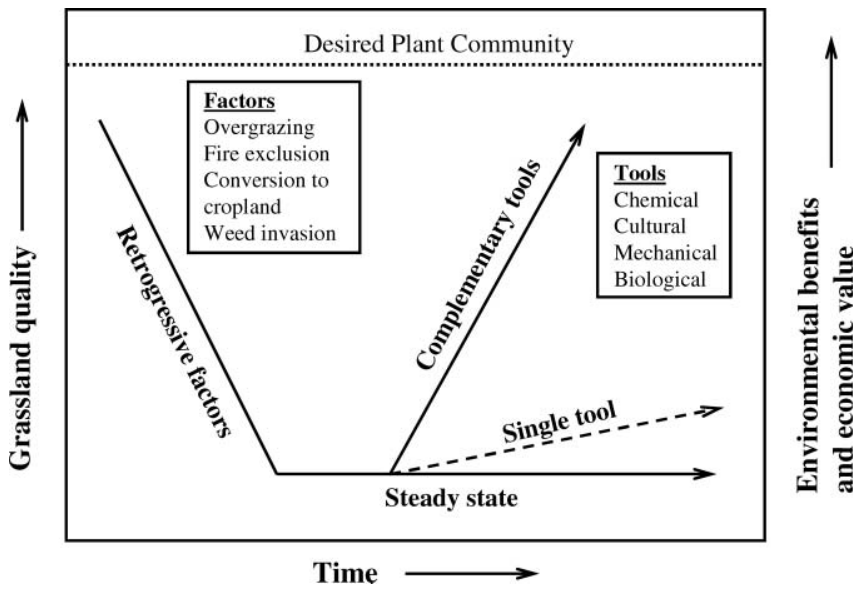

Figure 1. Generalized community succession model. Retrogression leads to a steady-state condition of lower diversity. Factors that lead community retrogression include overgrazing, exclusion of fire, conversion to cropland, and undesirable plant invasion. Reliance on a single technology results in slow rate of grassland recovery, while integrated use of complementary and possibly synergistic vegetation-management technologies (i.e., chemical, cultural, mechanical, and/or biological control measures) accelerates progress toward higher quality rangeland. ${ }^{8}$

unsustainable. Removing invasive plant species with mechanical, cultural, or chemical methods may only open niches for other undesirable species to become established unless desirable species are present to fill the vacated niches. ${ }^{3}$ In most cases, a successful long-term management program should be designed to include combinations of mechanical, cultural, biological, and chemical control techniques in an integrated approach (Fig. 1).

According to the National Road Map for Integrated Pest Management (http://www.ipmcenters.org/IPMRoadMap. pdf), IPM incorporates pest biology, environmental information, and available management technology in order to prevent unacceptable levels of pest damage using the most economical means, while posing the least possible risk to people, property, resources, and the environment. This definition applies to agricultural, residential, and non-crop areas, such as wildland and rangeland. It is important to note that the definition of IPM does not necessarily require that multiple control techniques be employed, nor does it imply that chemical control options should be avoided.

In rangelands, nearly all invasive-plant management strategies should use an IPM approach. The magnitude and complexity of rangeland invasions, combined with the costs for their control, most often necessitate the use of a combination of mechanical, cultural, biological, or chemical methods. These technologies can be used sequentially or in combination and should provide complimentary or synergistic control of the invasive plant in an economically and ecologically effective manner to meet management goals. ${ }^{3}$

Integrated invasive plant management, according to the definition of IPM, emphasizes the recovery of ecosystem function that can include energy flow, nutrient cycling, and water retention of the soil. This sustainable approach provides a context for managing invasive plants at an ecosystem-centered level, rather than focusing on the control of a specific invasive plant or on the use of a pest control technology. ${ }^{3}$ For this reason, all available tools should be considered during development of integrated weedmanagement programs, and those selected should optimize attainment of specific management objectives by the most economical means.

\section{Weed Control Methods}

Within an IPM context, selection of the proper management tool(s) and program can depend on a number of factors, including weed species, effectiveness of the control techniques, availability of biological control agents or grazing animals, length of time required for control, environmental considerations, chemical-use restrictions, topography, climatic conditions, and relative cost of the control techniques. There are numerous examples describing the effectiveness of an IPM approach for several invasive plants using a variety of control method combinations. ${ }^{1,5,8}$ The advantages and disadvantages of weed-control tools will vary depending on the invasive plant and the characteristics of the invaded site. The merits of each control measure should be considered when developing integrated weed management programs.

\section{Mechanical}

Mechanical control techniques either remove the entire plant or physically damage shoots, roots, or root crowns of plants to the point where they can no longer survive. Mechanical control methods include hand-pulling, hoeing, tilling, mowing, grubbing, chaining, cutting, and bulldozing. These techniques can be expensive, and they disrupt the soil, creating disturbed sites prone to invasion (for review see DiTomaso ${ }^{1}$ ).

Mowing is often used to control annuals, but can occasionally reduce seed production and can provide suppression of biennials and perennials, if used repeatedly. Timing is critical to the success of mowing. Typically, mowing or cutting perennial herbaceous or woody plants that reproduce vegetatively will stimulate production of new stems from vegetative buds below the cut surface. Tillage, chaining, bulldozing, grubbing, root-plowing (power grubbing), roller chopping, and shredding are more effective techniques to control woody species, but create disturbed sites that are often quickly occupied by invasive species. Tillage is not generally practiced on rangeland; it can spread perennial invasive plants by fragmenting and transporting vegetative reproductive structures such as rhizomes or creeping roots. Most mechanical treatments work best on relatively level terrain.

\section{Cultural}

Cultural control practices in rangelands most often include fire, grazing, or revegetation efforts. All these strategies 
require manipulating disturbance regimes to suppress invasive plants and to enhance desirable vegetation (for review see Masters and Sheley $^{3}$ ).

Fire has played an important role in the formation and maintenance of rangeland ecosystems. As with any disturbance, fire effects on ecosystems and invasive-plant management are influenced by its frequency, intensity, seasonal timing, and interactions with other disturbances. In general, prescribed fire is most successful for the control of lateseason annuals and will typically stimulate perennials that resprout from the base.

While overgrazing without periodic rest can selectively reduce desirable grass competitiveness and can increase invasive plants, appropriate grazing can shift a plant community toward more desired species. Because most animals have preferences for certain plants, grazing systems can be designed with different classes of livestock to increase utilization of some invasive plants. The level of selectivity also depends on stocking rates, as well as grazing intensity and frequency.

Revegetation or re-establishment of desirable and competitive plant species is the best long-term, sustainable method to suppress or inhibit plant invasions, while providing plants with greater forage value and enhanced wildlife habitat. When rangeland deterioration is severe and when few desirable species are present, it may be necessary to revegetate the site to reclaim the productive potential. In most cases, revegetation is expensive.

Revegetation is most successful when used as part of an IPM program. It is essential to control invasive plants in order to create an environment more conducive to establishment of desired vegetation that will fill the niche vacated by the controlled invader. ${ }^{3}$ Selecting the right species is critical to the success or failure of rangeland revegetation programs. Seeded species must be capable of establishing and should be adapted to soil conditions, elevation, and climate on the site. Planted species should be competitive with invasive plants, and they should contribute to improved ecosystem function. Land managers are often faced with the decision of whether to use native or introduced plant materials that differ in cost, establishment success, and resistance to reinvasion.

\section{Biological}

Classical biological control is used on some rangeland invasive plants and involves relocation of natural enemies of the invasive plant, typically insects, from their native habitats onto plants in their invaded habitats. The long-term goal of these programs is to exert sufficient stress on the target plant to reduce plant competitive ability and dominance. With insect agents this can be achieved by boring into roots, shoots, and stems, by defoliation, by seed predation, or by extracting plant fluids. Synchrony in the life cycles of host plant and agent, adaptation of the agent to a new climate and habitats, ability of the agent to find the host, capacity of the agent to reproduce rapidly, and the nature, extent, and timing of the damage caused by the biocontrol agent are among the factors that determine the effectiveness of the biocontrol agents.

While biological control efforts have targeted a number of habitats, the majority of released agents have been directed toward invasive plants of rangelands. ${ }^{9}$ Of the 72 examples worldwide where weed biocontrol programs have been underway for a sufficient period to assess control, only $28 \%$ have resulted in control that could be rated as sometimes complete, while $35 \%$ have shown no control of the target plant. ${ }^{10}$ Thus, despite its great benefits, biological control efforts are often unsuccessful. Overall, however, the numerous examples of successful biological control have made a great impact on the management of some important invasive plants.

Very little, if any, research has been conducted on trophic-level effects of introducing an exotic organism to control another exotic organism. Furthermore, once an insect is released into a new environment, it can pose a potential risk to native plants. Although most releases have proven to be safe, there are instances where introduced agents have utilized native plants. The seedhead weevil, Rbinocyllus conicus, introduced from Europe for the control of musk thistle (Carduus nutans) and other thistles, also reduced seed production in native Cirsium species. ${ }^{11}$

\section{Chemical}

Herbicides are generally classified by their mode of action, selectivity, and location of application (foliar or soil). Soil-applied herbicides generally target emerging seedlings, whereas foliar-applied herbicides control plants ranging from seedlings to fully mature plants.

On rangelands, herbicides are the most frequently used tool for the control of invasive plants. Unlike cropland environments where all plants except the crop are considered to be weeds, on rangelands there is often only one or a few invasive plants that are the target of control measures. These plants are generally growing in association with several desirable species. Thus, selectively is a key issue in an herbicide control program, and most herbicides are selective only within certain rates, environmental conditions, and methods of application.

Herbicides can be applied on rangeland by fixed-wing aircraft, helicopter, ground-application systems, backpack sprayers, or rope wick. The application method selected depends on the situation and the selectivity required. While nearly all rangeland herbicides are considered to have low toxicity to vertebrates and invertebrates, there are other risks including the potential for ground or surface water contamination, wind-blown herbicide movement on soil particles, and damage to desirable plants.

The most commonly used herbicides on rangelands are these: 1$)$ auxin-like growth regulators (2,4-D, aminopyralid, clopyralid, dicamba, fluroxypyr, picloram, and triclopyr) that selectively control broadleaf species; 2) glyphosate, a non-selective foliar-applied herbicide that has no activity in 
the soil; and 3) imidazolinone and sulfonylurea herbicides (chlorsulfuron, imazapic, imazapyr, metsulfuron, rimsulfuron, and sulfometuron) that disrupt the synthesis of amino acids essential for plant growth. The imidazolinone and sulfonylurea herbicides are phytotoxic at very low rates and have a broad range of selectivity spectrums that can be important in perennial-grass revegetation programs.

\section{Conclusion}

Technologies are available for managing invasive plants, but acceptable long-term control will only be achieved when integrated weed-management programs are incorporated into rangeland management plans. This includes the combined or sequential use of control tools that effectively manage the invasive plant while enhancing the desirable vegetation. Integrated weed management provides a context for managing pests that focuses on ecosystem processes and not on particular plant species or control practices. The merits of control measures and the potential for complementary or synergistic interactions when applying measures in appropriate sequences and combinations should be considered when developing integrated weed-management programs. Simply removing invasive plant species with selected control measures may only open niches for other undesirable species if aggressive desirable species are not available. An appropriate goal of invasive plant management should be to restore desirable native or introduced species communities that are resistant to future invasions. Prevention, detection, and control are key components of integrated management strategies. Early detection followed by prompt implementation of effective control measures is essential to eliminate the invader.

\section{References}

1. DiTomaso, J. M. 2000. Invasive weeds in rangelands: species, impacts, and management. Weed Science 48:255-265.
2. Mullin, B. H., L. W. J. Anderson, J. M. DiTomaso, R. E. Eplee, and K. D. Getsinger. 2000. Invasive plant species. Ames, IA, USA: Council for Agricultural Science and Technology Issue Paper No. 13. 18 p.

3. Masters, R. A., and R. L. Sheley. 2001. Principles and practices for managing rangeland invasive plants. Journal of Range Management 54:502-517.

4. Pimentel, D., R. Zuniga, and D. Morrison. 2005. Update on the environmental and economic costs associated with alien-invasive species in the United States. Ecological Economics 52:273-288.

5. DiTomaso, J. M., G. B. Kyser, J. R. Miller, S. Garcia, R. F. Smith, G. Nader, J. M. Connor, and S. B. Orloff. 2006. Integrating prescribed burning and clopyralid for the management of yellow starthistle (Centaurea solstitialis). Weed Science 54:757-782.

6. Sheley, R. L., and J. Krueger-Mangold. 2003. Principles for restoring invasive plant-infested rangeland. Weed Science 51:260-265.

7. Zamora, D. L., D. C. Thill, and R. E. Eplee. 1989. An eradication plan for plant invasions. Weed Technology 3:2-12.

8. Masters, R. A., and S. J. Nissen. 1998. Revegetating leafy spurge (Euphorbia esula L.)-infested grasslands with native tallgrasses. Weed Technology 12:381-390.

9. Julien, M. H. 1992. Biological control of weeds: a world catalogue of agents and their target weeds. New York, NY, USA: Academic Press. 186 p.

10. Sheppard, A. W. 1992. Predicting biological weed control. Trends in Ecology E Evolution 7:290-296.

11. Louda, S., D. Kendall, J. Connor, and D. Simberloff. 1997. Ecological effects of an insect introduced for the biological control of weeds. Science 277:1088-1090.

Authors are Cooperative Extension Specialist, Dept of Plant Sciences, University of California, Davis, CA 95616, USA, jmditomaso@ucdavis.edu (DiTomaso); and Research Scientists, Dow AgroSciences, LLC, Indianapolis, IN 46268, USA (Masters and Peterson). 